\title{
An Engineered Zinc Finger Protein Activator of the Endogenous Glial Cell Line-Derived Neurotrophic Factor Gene Provides Functional Neuroprotection in a Rat Model of Parkinson's Disease
}

\author{
Josee Laganiere, ${ }^{\star \star}$ Adrian P. Kells, ${ }^{2 \star}$ Jeffrey T. Lai, ${ }^{1}$ Dmitry Guschin, ${ }^{1}$ David E. Paschon, ${ }^{1}$ Xiangdong Meng, ${ }^{1}$ \\ Lauren K. Fong, ${ }^{1}$ Qi Yu, ${ }^{1}$ Edward J. Rebar, ${ }^{1}$ Philip D. Gregory, ${ }^{1}$ Krystof S. Bankiewicz, ${ }^{2}$ John Forsayeth, ${ }^{2}$ \\ and H. Steve Zhang ${ }^{1}$ \\ ${ }^{1}$ Sangamo BioSciences, Point Richmond Tech Center, Richmond, California 94804, and 2Department of Neurological Surgery, University of California, San \\ Francisco, San Francisco, California 94143
}

\begin{abstract}
Loss of dopaminergic neurons is primarily responsible for the onset and progression of Parkinson's disease (PD); thus, neuroprotective and/or neuroregenerative strategies remain critical to the treatment of this increasingly prevalent disease. Here we explore a novel approach to neurotrophic factor-based therapy by engineering zinc finger protein transcription factors (ZFP TFs) that activate the expression of the endogenous glial cell line-derived neurotrophic factor (GDNF) gene. We show that GDNF activation can be achieved with exquisite genome-wide specificity. Furthermore, in a rat model of PD, striatal delivery of an adeno-associated viral vector serotype 2 encoding the GDNF activator resulted in improvements in forelimb akinesia, sensorimotor neglect, and amphetamine-induced rotations caused by 6-hydroxydopamine (6-OHDA) lesion. Our results suggest that an engineered ZFP TF can drive sufficient GDNF expression in the brain to provide functional neuroprotection against 6-0HDA; therefore, targeted activation of the endogenous gene may provide a method for delivering appropriate levels of GDNF to PD patients.
\end{abstract}

\section{Introduction}

Parkinson's disease (PD) is a chronic, progressive neurological disorder with increasing incidence in the aging population. Currently, the standard of care for PD patients is levodopa, which brings only symptomatic relief early in the treatment course, and its long-term use is limited by side effects. Because motor impairment, as well as psychiatric symptoms, seen in PD patients derive primarily from dopaminergic neuron death, methods that aim to protect and/or regenerate dopaminergic neurons hold tremendous promise for halting or even reversing PD progression. The most studied neurotrophins in this respect are members of the basic fibroblast growth factor superfamily (Airaksinen et al., 1999), of which the prime therapeutic candidate is glial cellderived neurotrophic factor (GDNF), first isolated from the B49 cell line based on its ability to promote the survival of embryonic dopaminergic neurons in vitro (Engele and Bohn, 1991; Lin et al.,

\section{Received May 3, 2010; revised Sept. 15, 2010; accepted 0ct. 9, 2010.}

This work was funded by a Therapeutic Development Initiative grant from the Michael J. Fox Foundation for Parkinson's Research to H.S.Z. We thank Lei Zhang and Jeffrey Miller for ZFP design, Sarah Hinkley, Gladys Dulay, Stephen Lam, and Rainier Amora for ZFP assembly, and Irina Ankoudinova for technical assistance. We also thank Susan Abrahamson for careful reading of the manuscript.

*J.L. and A.P.K. contributed equally to this work.

J.L., J.T.L., D.G., D.E.P., X.M., L.K.F., Q.Y., E.J.R., P.D.G., and H.S.Z. are employees of Sangamo BioSciences Inc.

Correspondence should be addressed to H. Steve Zhang, Sangamo BioSciences, Point Richmond Tech Center, 501 Canal Boulevard, Suite A100, Richmond, CA 94804. E-mail: szhang@sangamo.com.

DOI:10.1523/JNEUROSCI.2440-10.2010

Copyright $\odot 2010$ the authors $\quad$ 0270-6474/10/3016469-06\$15.00/0
1993). GDNF and its family members act through a receptor composed of a GFR GPI-linked receptor that binds the neurotrophic factor, which in turn activates the transmembrane c-ret tyrosine kinase (Airaksinen et al., 1999) and perhaps other signaling molecules (Sariola and Saarma, 2003). A multitude of preclinical studies with GDNF protein in an array of rat, mouse, and monkey models of PD have demonstrated potent effects of this factor in protecting dopaminergic neurons from neurotoxininduced cell death and in ameliorating indices of dopaminedependent behaviors (Grondin et al., 2003). Therapies based on direct administration of neurotrophic factors have, therefore, been under intense investigation. However, despite extensive positive data from preclinical animal studies (Peterson and Nutt, 2008) and encouraging results from phase I clinical trials of recombinant GDNF and adeno-associated viral vector (AAV)Neurturin (NTN), results from phase II studies have been disappointing (Gill et al., 2003; Slevin et al., 2005; Lang et al., 2006). It has been postulated that lack of clinical efficacy, as well as some side effects, resulted in part from the high focal levels of the therapeutic factor delivered and/or suboptimal delivery methods. GDNF is a potent neurotrophic factor, and small changes in its expression levels can have profound effects on neuronal survival. In adult mice for example, an $\sim 60 \%$ decrease in the endogenous GDNF level is sufficient to cause progressive hypokinesia and significant neuronal cell death (Pascual et al., 2008). On the other hand, toxicity (including reduced food consumption and body weight, as well as multifocal cerebellar Pur- 
kinje cell loss) has been observed in rhesus monkeys that received intraputamenal infusion of high concentrations of GDNF (Hovland et al., 2007), suggesting the importance of physiologically relevant doses of GDNF to achieve both safety and efficacy.

To explore new strategies exploiting the neurotrophic activity of GDNF within this therapeutic window, we set out to activate GDNF expression from its endogenous gene. Transcription factors, based on $\mathrm{Cys}_{2}-\mathrm{His}_{2}$ zinc finger proteins (ZFPs), can be engineered to specifically target virtually any gene (Jamieson et al., 2003). By targeting the endogenous gene and exploiting the native promoter, which imposes a physiological upper limit on the level of gene expression from each allele, a ZFP can produce sufficient, but not supraphysiological, levels of the therapeutic protein needed to achieve both long-term efficacy and safety. Here we sought to determine whether the endogenous GDNF gene could be specifically regulated by engineered ZFP activators, and whether such activation would confer functional neuroprotection in vivo.

\section{Materials and Methods}

Generation of ZFP activators of the GDNF gene. Six-finger ZFPs designed to target the rat, human, and rhesus GDNF promoters were assembled by PCR linking three two-finger modules (Moore et al., 2001a,b); the resultant ZFP coding sequence was cloned into the pcDNA3.1 vector (Invitrogen) as a fusion with the activation domain of the NF- $\kappa$ B p 65 subunit (Yokoi et al., 2007). The targeting sequence of rGDNF-ZFP is tgGGGGGCGCGGAACCGGGAgg (chr2:57,398,742-57,398,763, the Nov. 2004 assembly of the rat genome), and that of hGDNF-ZFP is ttACATGGCAGGCAATGAAGaa (chr5:37,840,891-37,840,908, the GRCh37 assembly of the human genome, and chr6:37,682,748-37,682,765, the Jan. $2006 \mathrm{draft}$ assembly of the rhesus macaque genome). The uppercase letters in the binding sites denote bases directly contacted by the ZFP, and lowercase letters denote $2 \mathrm{bp}$ of flanking sequence.

Cell culture and transfection. Rin-m5F, C6, LLC-MK2, RF6A, HEK293, HEK293T, and U87MG cells were purchased from ATCC and cultured as suggested. LLC-MK2 cells were transfected with Nucleofector (Lonza) program A-23. Rin-m5F and RF6A cells were transfected with the Nucleofector 96-well shuttle (Lonza) in SF solution using program EH100 , and C6 cells were transfected in SF solution using the FF-137 program. HEK293, HEK293T, and U87MG cells were transfected using Fugene6 (Roche). Rat striatal cells (Sprague/Dawley, E18) were purchased from Genlantis and seeded in Neurobasal media (Invitrogen) supplemented with B27 (Invitrogen) and $0.5 \mathrm{~mm}$ glutamine. After $3 \mathrm{~d}$, half of the medium was replenished and the culture was maintained for 3-4 additional days before infection with lentiviral vectors.

Lentivirus preparation and infection. Lentiviral vectors were prepared by transient transfection of 293T cells as described previously (Tiscornia et al., 2006). Infection with lentivirus expressing the ZFP or GFP was performed at multiplicity of infection of 5. Gene expression and ELISA assays were performed $48 \mathrm{~h}$ after infection.

Gene expression analyses. Total RNA was isolated with High Pure RNA Isolation Kit (Roche) $48 \mathrm{~h}$ after transfection. Real-time RT-PCR analyses were performed as previously described (Liu et al., 2001). The primer/ probe sets for rat GDNF (Rn00569510_m1), rat ACTB ( $\beta$-actin) (4352931E), human GDNF (Hs01055329_m1), and human ACTB (4352935E) were purchased from Applied Biosystems. Primer and probe sequences for $18 \mathrm{~S}$ and rhesus GDNF are available upon request.

Microarray analysis. HEK293 cells were transfected with hGDNF-ZFP or the pcDNA control in triplicate, and the Affymetrix GeneChip Human Genome U133 Plus 2.0 chips were used for whole-genome expression profiling. Messenger RNA was amplified with Affymetrix one-cycle labeling and amplification kit. Chips were washed, stained, and scanned with Affymetrix fluidic station and scanner. Data mining was performed with the RMA method for primary signal processing with the GeneSpring10 program from Agilent.

In vivo adeno-associated virus serotype 2 experiments. Adenoassociated virus serotype 2 (AAV2) vectors were produced by means of
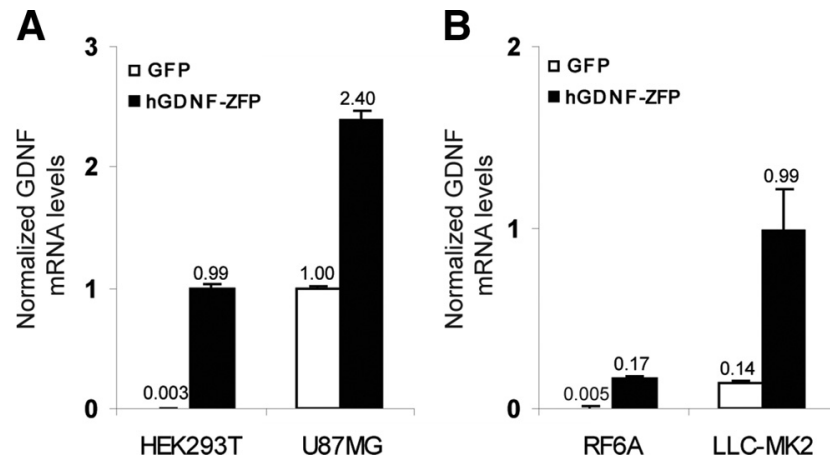

Figure 1. Activation of human and rhesus macaque GDNF in cultured cells. $\boldsymbol{A}$, HEK293T and U87MG cells were transiently transfected with plasmids encoding hGDNF-ZFP or GFP and harvested $48 \mathrm{~h}$ later for mRNA analysis by quantitative RT-PCR. The ratio of GDNF/ $\beta$-actin mRNA levels, normalized to that of untransfected U87MG cells, is shown. $B$, LLC-MK2 and RF6A cells were transfected with the same plasmids as above and GDNF mRNA levels analyzed as described in $\boldsymbol{A}$, except that 18S RNA was used as an internal control.

the triple transfection method (Matsushita et al., 1998). Vectors were infused bilaterally into the striatum $\left(10 \mu \mathrm{l}\right.$ of a $1 \times 10^{13}$ vector genome per milliliter of solution per striatum) of adult rats ( $n=6$ per group) by convection-enhanced delivery (CED) as described previously (Oiwa et al., 2003). Four weeks after vector delivery, $10 \mu \mathrm{g}$ of 6-hydroxydopamine (6-OHDA) suspended in $20 \mu \mathrm{l}$ of sterile saline with $0.2 \% \mathrm{w} / \mathrm{v}$ ascorbate was infused into the right striatum by CED. Rats were killed 7 weeks after AAV2-rGDNF-ZFP delivery. The right striata were dissected and frozen rapidly for GDNF ELISA, the left striata were dissected and frozen rapidly for mRNA quantification, and the posterior halves of the brains were postfixed in $4 \%$ paraformaldehyde for tyrosine hydroxylase (TH) immunostaining.

Rat behavior testing. Forelimb akinesia was assessed with the cylinder test (Schallert et al., 2000). Briefly, rats were individually placed in a vertical cylinder, and placement of their left and right forepaws on the walls of the cylinder was counted as they explored the novel environment. The first 20 forepaw placements were assessed $14 \mathrm{~d}$ after 6-OHDA. Sensorimotor neglect was assessed in the corridor task (Fitzsimmons et al., 2006), in which retrieval of food from left or right side of a corridor was monitored. The first 20 food retrievals were recorded $9 \mathrm{~d}$ after 6-OHDA administration. Amphetamine-induced rotational behavior was tested $15 \mathrm{~d}$ after 6-OHDA injection. Rats were placed in an automated rotameter following intraperitoneal administration of D-amphetamine $(5 \mathrm{mg} / \mathrm{kg})$, and the total number of rotations in $1 \mathrm{~h}$ was recorded.

GDNF ELISA. For detection of GDNF levels in vivo, rat striatum was dissected from each hemisphere, snap frozen in liquid nitrogen, and homogenized with a model 100 Fisher Science Dismembrator in $300 \mu \mathrm{l}$ of lysis buffer (Tropix, Applied Biosciences) supplemented with protease inhibitors (Mini Complete, Roche) and then centrifuged for $15 \mathrm{~min}$ at $13,000 \times g$ at $4^{\circ} \mathrm{C}$. Concentrations of GDNF were determined with a commercially available kit (Promega) following the manufacturer's instructions, but substituting Supersignal substrate solution (Pierce) where appropriate. Chemiluminescence was measured on a Flx800 microplate reader (Biotek) or a Wallac Victor2 instrument (PerkinElmer) and expressed as relative light units. For detection of GDNF secreted by cultured cells, $100 \mu \mathrm{l}$ of conditioned medium was used for each ELISA reaction.

Tyrosine hydroxylase immunohistochemistry. Coronal sections containing the medial forebrain bundle (MFB) and substantia nigra were cut on a sliding microtome $(40 \mu \mathrm{m})$ and stained for TH. Serial free-floating sections $(240 \mu \mathrm{m}$ interval) were incubated overnight with a monoclonal anti-TH antibody (Millipore Bioscience Research Reagents, MAB318, 1:1000) and Mach 2 mouse HRP-polymer (Biocare Medical) and stained with DAB substrate (Vector). Images of the left and MFB were captured with a $10 \times$ objective, and the intensity of TH staining was quantified with ImageJ software (NIH). To account for intersection variation in staining, a background image was captured from an area devoid of $\mathrm{TH}$ 
Table 1. Microarray analysis of the gene expression changes after transfection of HEK293 cells with the hGDNF activator

\begin{tabular}{|c|c|c|c|c|c|}
\hline Gene abbreviation & Gene name & Probe & $p$ value & Fold regulation & Regulation \\
\hline \multicolumn{6}{|l|}{$24 \mathrm{~h}$} \\
\hline GDNF & Glial cell-derived neurotrophic factor & 230090_at & $1.59 \times 10^{-4}$ & 4.48 & up \\
\hline \multicolumn{6}{|l|}{$48 \mathrm{~h}$} \\
\hline GDNF & Glial cell-derived neurotrophic factor & 230090_at & $5.57 \times 10^{-5}$ & 4.19 & up \\
\hline FLJ37786 & Hypothetical LOC642691 & 1558579_at & $5.68 \times 10^{-5}$ & 3.26 & up \\
\hline LOC387763 & Hypothetical LOC387763 & 227099_s_at & $3.83 \times 10^{-4}$ & 2.15 & up \\
\hline
\end{tabular}

In two independent experiments, HEK293 cells were transiently transfected with the hGDNF-ZFP vector or pcDNA in triplicate. Total RNA was purified 24 or $48 \mathrm{~h}$ after transfection and subjected to the whole-genome Affymetrix GeneChip Human Genome U133 Plus 2.0 analysis. The genes that met the predetermined criteria of more than twofold change in expression levels and $p<0.005$ at 24 and $48 \mathrm{~h}$ are listed.

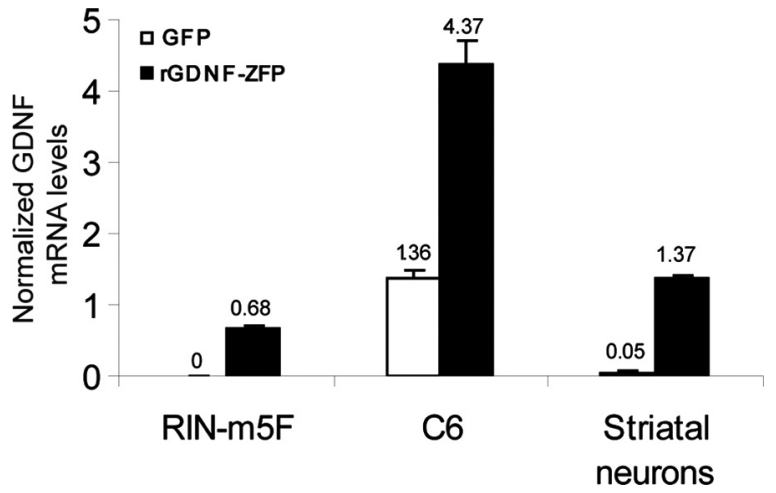

Figure 2. Activation of rat GDNF expression in cultured cells. RIN-m5F and C6 cells were transiently transfected with plasmids encoding rGDNF-ZFP or GFP; rat striatal neurons were infected with lentiviral vectors encoding either GFP or rGDNF-ZFP. Cells were harvested $48 \mathrm{~h}$ after transfection or infection for $m R N A$ analysis by quantitative RT-PCR. The ratio of GDNF/ $\beta$ actin mRNA levels, normalized to that of untransfected C 6 cells, is shown.
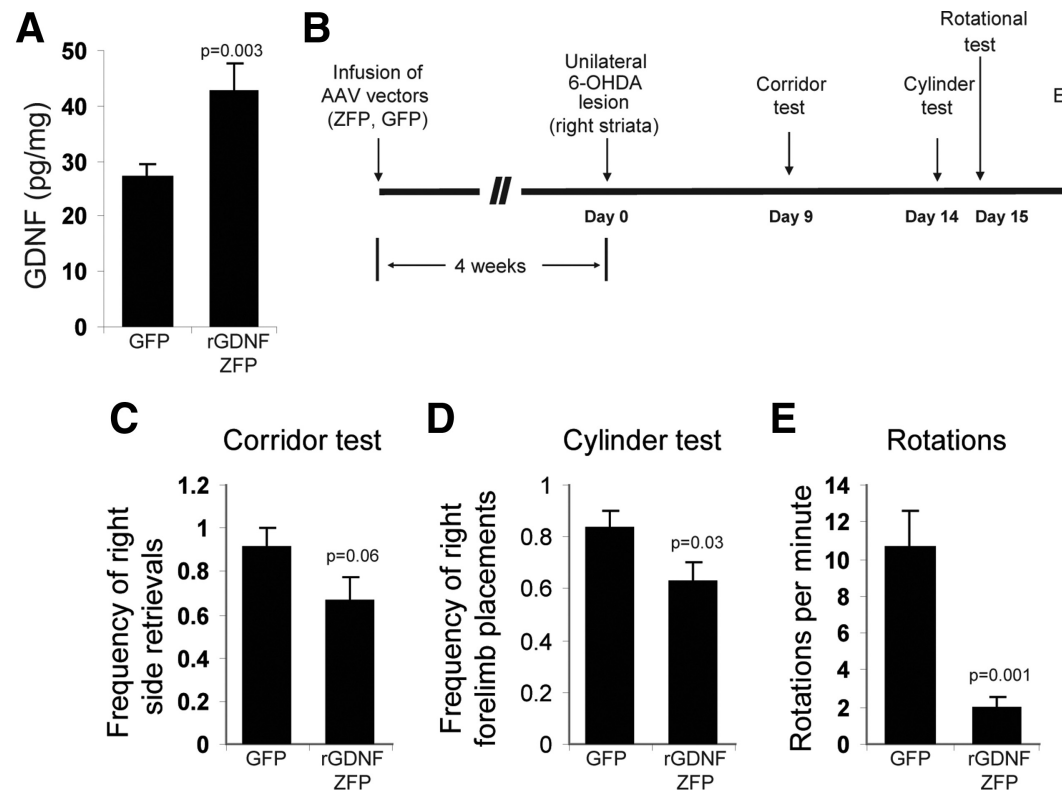

Figure 3. Activation of the GDNF gene in vivo and functional neuroprotection by the ZFP activator in the 6-OHDA model of Parkinson's disease. A, AAV2-GFP or AAV2-rGDNF-ZFP ( $n=3$ for each group) were infused into striatum of normal rats by CED. Striatal GDNF protein levels were analyzed by ELISA 4 weeks after infusion. $B$, Schematic timeline of the 6-OHDA experiment $(n=$ 6 for AAV2-GFP and AAV2-rGDNF-ZFP). C, The frequency of food retrieval from the right (ipsilateral) side was recorded for a total of 20 attempts for each rat in the corridor test. $\boldsymbol{D}$, Frequency of right forelimb use was recorded for the first 20 wall contacts made by each rat in the cylinder test. $\boldsymbol{E}$, Number of rotations per minute was recorded after intraperitoneal administration of $10 \mu \mathrm{g}$ of amphetamine.

staining, and the gray-scale pixel intensity was subtracted from the MFB images. The TH intensity in the right MFB and $\mathrm{SN}$ is reported as an averaged percentage of the left (unlesioned) MFB TH staining intensity measured on three sections per animal.
Statistical analysis. All statistical assessments were performed using one-tailed $t$ tests.

\section{Results \\ An engineered ZFP TF activates the endogenous human GDNF gene}

A panel of six-finger ZFP DNA-binding domains (DBDs) was assembled to target conserved regions within the human and rhesus GDNF promoter wherein each DBD recognizes a unique 18 bp site within the human genome. The assembled DBDs were then linked to the NF- $\kappa \mathrm{B}$ p 65 activation domain to generate candidate ZFP TF activators of GDNF. Their ability to activate the endogenous GDNF gene was tested by transient transfection of HEK293T cells, followed by real-time RT-PCR analysis of GDNF mRNA. The lead ZFP (referred to as hGDNF-ZFP) that consistently gave the highest activation $(\sim 300$-fold $)$ of GDNF mRNA in multiple experiments was chosen for further study (Fig. 1A). Upregulation of GDNF mRNA by hGDNF-ZFP (2.4-fold) was also observed in U87MG glioblastoma cells, which express high basal levels of GDNF (Fig. 1A). In both cases, parallel increases in secreted GDNF protein were observed (data not shown). The fold of activation in U87MG cells (high basal GDNF expression) is lower than that achieved in HEK293T cells (low basal GDNF expression), consistent with the notion that a physiological upper limit of expression from the endogenous gene was being approached.

Since hGDNF-ZFP was designed to recognize a site that is fully conserved between human and rhesus macaque, the ability of hGDNF-ZFP to activate rhesus GDNF was also tested by transient transfection in two rhesus macaque cell lines. We found that hGDNF-ZFP drove $\sim 35$ and $\sim 10$-fold upregulation of GDNF mRNA in RF-6A and LLC-MK2 cells, respectively (Fig. $1 B$ ). Together, these data demonstrate that hGDNF-ZFP is a potent activator of GDNF in multiple cell types derived from human or rhesus macaque.

\section{The human GDNF activator is}

highly specific

Having established that hGDNF-ZFP could drive significant GDNF activation, we next evaluated its functional specificity. Independent microarray experiments were performed to compare the genome-wide expression profiles of HEK293 cells transfected with the hGDNF-ZFP plasmid or the empty vector. 
We found that $24 \mathrm{~h}$ after transfection, among the 47,000 transcripts represented on the Affymetrix chip, GDNF (4.48-fold up, $p=0.00015)$ was the only gene that met the predefined criteria for a change in gene expression (i.e., more than twofold change in expression level, $p<0.005$ ) (Table 1 ). In a second independent experiment, in which expression profiles were examined $48 \mathrm{~h}$ after transfection, GDNF was the most highly regulated gene ( $\sim 4.2$-fold, $p<0.001$ ), and only two other genes were coregulated when the same criterion was used (Table 1). These results demonstrate that the hGDNF-ZFP functions with high specificity genome-wide.

\section{ZFP-driven activation of rat GDNF}

To determine whether increased GDNF production from the endogenous gene was sufficient to confer neuroprotection to dopaminergic neurons in vivo, we chose the rat as a model for efficacy testing. Despite the fact that the human and rat GDNF promoters share $\sim 75 \%$ identity, there are few contiguous stretches of conserved sequence ( $18 \mathrm{bp}$ or longer) that allow a single ZFP to be designed for targeting both species. The binding site for hGDNFZFP is not conserved in rat, and hGDNF-ZFP predictably does not activate GDNF in rat cells (data not shown). We designed and assembled a panel of ZFP activators specific to the rat GDNF promoter and tested their activity by transient transfection in rat insulinoma RIN-m5F cells. The engineered transcription factor that gave the highest levels of GDNF activation in multiple transfections (rGDNF-ZFP) was selected for further studies (Fig. 2). GDNF mRNA was undetectable in RIN-m5F cells by RT-PCR, upon activation by rGDNF-ZFP it reached $\sim 70 \%$ of that in C6 glioma cells, which express high basal levels of GDNF. When rGDNF-ZFP was tested in C6 glioma cells, an approximately threefold increase in GDNF mRNA (Fig. 2) was observed with a parallel increase in secreted GDNF levels (data not shown). Thus, like hGDNF-ZFP described above, rGDNF-ZFP drives higher fold of activation in cells with low basal GDNF expression (RIN$\mathrm{m} 5 \mathrm{~F}$ ) than in cells with high basal expression (C6), again consistent with the notion that there is a natural "cap" on the expression level supported by the endogenous GDNF promoter. Because we intended to deliver rGDNF-ZFP to the rat striatum for in vivo testing, we wished to confirm the activity of the ZFP in the target cell type. Cultured primary rat striatal neurons were infected with lentiviral vectors expressing rGDNF-ZFP or GFP. The rGDNFZFP led to $>20$-fold increase in GDNF mRNA levels (Fig. 2) and similar increase in secreted GDNF levels (data not shown). These results demonstrate that the rat GDNF gene can be activated by an engineered ZFP.

\section{The ZFP activator of GDNF provides functional neuroprotection in the rat 6-OHDA model of Parkinson's disease}

AAV2 vectors transduce neurons effectively in vivo, and their safety in the brain has been demonstrated in multiple clinical trials (Eberling et al., 2008; Fiandaca et al., 2008; Christine et al., 2009). Therefore, we selected AAV2 as the delivery vehicle for in vivo efficacy testing of the GDNF activator. AAV2 vectors encoding either the rGDNF-ZFP or GFP were infused into normal rat striatum by CED. Four weeks after infusion, striatal GDNF levels were $\sim 60 \%$ higher in ZFP-treated rats $(42.8 \pm 4.7 \mathrm{pg} / \mathrm{mg}$ total protein) compared to control (GFP-treated) rats $(27.1 \pm 2.2$ $\mathrm{pg} / \mathrm{mg}$ total protein) $(p=0.003)$, confirming the activity of the GDNF activator in vivo (Fig. $3 A$ ). Next, we used the 6-OHDA lesion model to determine whether a ZFP-driven increase in expression of GDNF from the endogenous gene would prevent
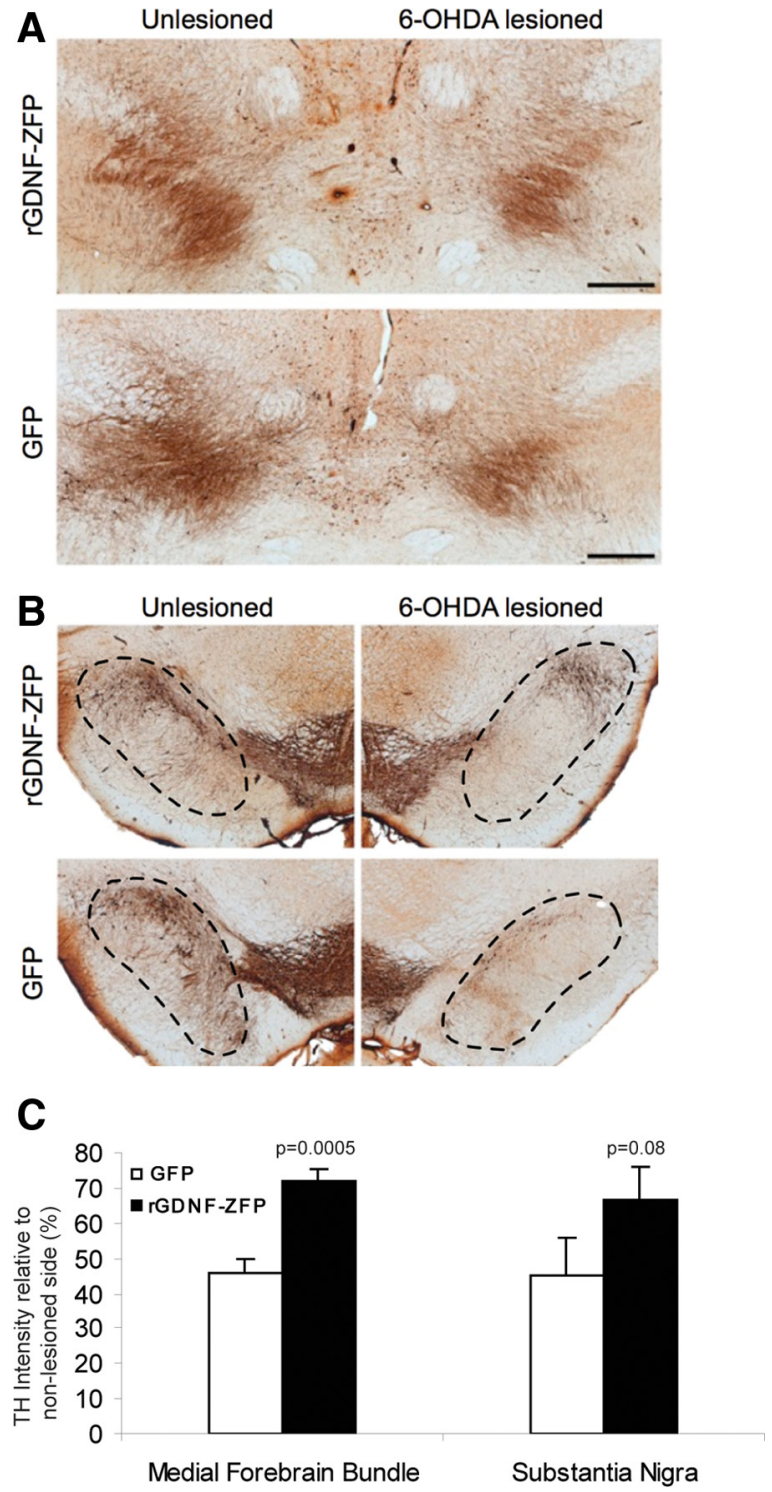

Figure 4. Preservation of TH expression in 6-OHDA-lesioned nigrostriatal neurons by rGDNFZFP. TH immunostainings show that in the medial forebrain bundle $(\boldsymbol{A})$ and substantia nigra $(\boldsymbol{B})$, AAV2-rGDNF-ZFP preserved TH expression in the lesioned hemisphere relative to that of the unlesioned side. Scale bars, $500 \mu \mathrm{m}$. C, The intensity of TH staining was quantified by densitometry and displayed as ratio of lesioned/unlesioned side. ( $n=6$ rats per group).

behavioral defects associated with loss of dopaminergic neurons. AAV2-rGDNF-ZFP or AAV2-GFP control vectors were infused bilaterally into the striatum of adult rats ( $n=6$ per group) by CED. Four weeks after vector delivery, $10 \mu \mathrm{g}$ of 6 -OHDA was infused into the right striatum by CED, triggering the loss of dopaminergic neurons in the ipsilateral substantia nigra that is manifested by a series of behavioral abnormalities (Oiwa et al., 2003). Our experimental design for examining the effect of AAV2-rGDNF-ZFP on 6-OHDA-induced defects is shown in Figure $3 B$.

Nine days after 6-OHDA administration, we assessed the sensorimotor activity of the rats in the "corridor test," in which unilaterally lesioned animals exhibit a bias toward the lesioned side for food retrieval (Fitzsimmons et al., 2006). As shown in Figure $3 C$, rats that received 6-OHDA and AAV2-GFP displayed a strong ipsilateral preference and a contralateral sensorimotor neglect, retrieving food from the right side of the corridor $>90 \%$ 
of the time, whereas AAV2-rGDNF-ZFP-treated rats showed less bias, retrieving food from the right side of the corridor only $66 \pm$ $11 \%$ of the time $(p=0.06)$. Fourteen days after 6-OHDA infusion, spontaneous forelimb usage was measured in the "cylinder test" (Schallert et al., 2000). AAV2-GFP-treated rats showed a strong preference $(83 \pm 7 \%)$ for the right forelimb, while significant correction $(62 \pm 8 \%, p=0.03)$ was observed in rats that received AAV2-rGDNF-ZFP (Fig. 3D). Finally, $15 \mathrm{~d}$ after 6-OHDA administration, rats were subjected to a drug-induced rotational test, in which rats with unilateral substantia nigra lesion rotate toward the lesioned side after intraperitoneal injection of amphetamine (Oiwa et al., 2003). AAV2-rGDNF-ZFP-treated rats exhibited a significant reduction in the rotational behavior $(2.0 \pm 0.6$ rotations $/ \mathrm{min})$ compared to the AAV2-GFP-treated rats $(10.6 \pm 2.0$ rotations $/ \mathrm{min})(p=0.001)$ (Fig. $3 E)$.

Upon completion of the behavioral tests, rats were killed and the brains collected for analysis. The striata were used for protein quantification, and the midbrain region for immunohistochemistry. Elevated GDNF protein levels (34.9 $\pm 4.5 \mathrm{pg} / \mathrm{mg}$ total protein for ZFP-treated rats compared to $26.3 \pm 3.4 \mathrm{pg} / \mathrm{mg}$ total protein, $p=0.004$ ) were maintained in the lesioned (right) striatum of AAV2-rGDNF-ZFP-treated animals 7 weeks after ZFP TF delivery. To further analyze changes in the nigrostriatal dopaminergic neurons, sections through the MFB (Fig. 4A) and substantia nigra (Fig. $4 B$ ) were stained for $\mathrm{TH}$. TH density within the right MFB of control animals was only $46 \pm 4 \%$ of the unlesioned (left) MFB, whereas AAV2-rGDNF-ZFP-treated animals had significantly enhanced preservation of TH-positive fibers $(72 \pm 3 \%$; $p=0.001$ ) (Fig. 4C). Similar observations were found in the substantia nigra, where $\mathrm{TH}$ density in the right hemisphere of control animals was $45 \pm 11 \%$ of the left hemisphere, compared to $67 \pm 9 \%$ in AAV2-rGDNF-ZFP-treated animals $(p=0.08)$ (Fig. 4C). Consistent with the protection of the TH-positive cells on the lesioned hemisphere, we also observed that rGDNF-ZFP led to an approximately fourfold increase of TH mRNA in the unlesioned striatum compared to the GFP control, suggesting that rGDNF-ZFP delivered to the striatum has significant local effects on maintaining the terminals of the dopaminergic neurons and/or dopaminergic neurons that are intrinsic to the striatum. Together, these results demonstrate that the ZFP transcription factor can activate the endogenous GDNF gene and maintain TH-positive neurons in vivo and is functionally protective in the 6-OHDA rat model of PD.

\section{Discussion}

Most preclinical and clinical testing of GDNF and its family member NTN has focused on direct delivery of high concentrations of recombinant protein or viral vector-based cDNA overexpression. However, there is evidence suggesting that supraphysiological levels of GDNF maintained long term may not be the best method of providing trophic support for dopaminergic neurons in vivo. For example, chronic putamenal infusion of recombinant GDNF caused reduced food consumption and body weight, as well as Purkinje cell loss in rhesus monkeys (Hovland et al., 2007); overexpression of GDNF cDNA in the substantia nigra led to severe weight loss in rodents (Manfredsson et al., 2009a,b) and monkeys (Su et al., 2009).

Our study demonstrates an alternative means of augmenting GDNF expression that produces more physiologically relevant levels of GDNF. Engineered ZFP TFs drive significant activation of the endogenous GDNF gene in multiple cell types. The relative extent of activation was inversely correlated with the basal GDNF levels of tested cells, supporting our hypothesis that the natural promoter architecture and chromatin context impose a physiological upper limit on mRNA output from endogenous genes. Such a limit may in effect prevent supraphysiological levels of GDNF from being produced, and our results suggest that this "ceiling" of expression from the GDNF locus was approached by the engineered ZFP activators. Importantly, the modest overall increase of striatal GDNF levels provoked by the ZFP was sufficient to provide marked improvement in all behavioral tests performed in the 6-OHDA rat model of PD. For example, in the most sensitive amphetamine-induced rotation test, the improvement by the ZFP was comparable to that seen with the delivery of high doses of AAV vectors encoding GDNF or neurturin in the same model (Gasmi et al., 2007), suggesting that therapeutic levels of GDNF may be far lower than those produced by conventional approaches. Indeed, our finding that an $\sim 60 \%$ increase over the basal striatal GDNF level is efficacious in protecting against 6-OHDA-induced motor defects mirrors the observation that an $\sim 60 \%$ decrease in the endogenous GDNF level in adult mouse brain is sufficient to cause progressive hypokinesia and significant neuronal cell death (Pascual et al., 2008). The functional neuroprotection by the GDNF activator in the 6-OHDA model is supported by immunohistochemical demonstration of preservation of TH-positive nigrostriatal neurons. Our observation that the GDNF activator increased TH mRNA in the striatum implies that maintenance or enhanced sprouting of surviving $\mathrm{TH}$ positive fibers and/or dopaminergic neurons within the striatum may also contribute to preserve normal function as previously observed after AAV2-GDNF delivery in MPTP-treated nonhuman primates (Kells et al., 2010).

Although our study showed that activation of endogenous GDNF is sufficient to protect against 6-OHDA lesion in rat, demonstration of efficacy and safety in a nonhuman primate model of PD will likely be required for advancing the ZFP-based approach to the clinic. The dual species-specific (human and rhesus macaque) GDNF activator that we engineered enables such studies. Importantly, we have shown by whole-genome microarray analysis that the human/rhesus GDNF activator is highly specific, which bodes well for the safety and tolerability of long-term ZFP TF expression in the brain.

Another key aspect of neurotrophic factor-based therapy is the efficiency with which therapeutic modalities can be delivered. Based on monkey studies, it was estimated that the infusion protocol used in a failed phase 2 clinical trial may have only covered $2-9 \%$ of the putamen in human subjects (Salvatore et al., 2006). We have shown that CED, which was used in this study to deliver AAV-ZFP to the rat brain, can provide near-complete coverage of the monkey putamen (Eberling et al., 2009). Given the potency of GDNF in protecting neuronal survival, we envision that a therapeutically relevant (but not supraphysiological) level of GDNF that is well distributed throughout putamen is critical for both clinical efficacy and safety. Engineered ZFP activators that drive specific activation of endogenous GDNF combined with highly efficient CED delivery may provide a solution to realize the therapeutic potential of this well studied neurotrophic factor.

\section{References}

Airaksinen MS, Titievsky A, Saarma M (1999) GDNF family neurotrophic factor signaling: four masters, one servant? Mol Cell Neurosci 13:313-325.

Christine CW, Starr PA, Larson PS, Eberling JL, Jagust WJ, Hawkins RA, VanBrocklin HF, Wright JF, Bankiewicz KS, Aminoff MJ (2009) Safety and tolerability of putaminal AADC gene therapy for Parkinson disease. Neurology 73:1662-1669.

Eberling JL, Jagust WJ, Christine CW, Starr P, Larson P, Bankiewicz KS, 
Aminoff MJ (2008) Results from a phase I safety trial of hAADC gene therapy for Parkinson disease. Neurology 70:1980-1983.

Eberling JL, Kells AP, Pivirotto P, Beyer J, Bringas J, Federoff HJ, Forsayeth J, Bankiewicz KS (2009) Functional effects of AAV2-GDNF on the dopaminergic nigrostriatal pathway in parkinsonian rhesus monkeys. Hum Gene Ther 20:511-518.

Engele J, Bohn MC (1991) The neurotrophic effects of fibroblast growth factors on dopaminergic neurons in vitro are mediated by mesencephalic glia. J Neurosci 11:3070-3078.

Fiandaca MS, Forsayeth JR, Dickinson PJ, Bankiewicz KS (2008) Imageguided convection-enhanced delivery platform in the treatment of neurological diseases. Neurotherapeutics 5:123-127.

Fitzsimmons DF, Moloney TC, Dowd E (2006) Further validation of the corridor task for assessing deficit and recovery in the hemi-Parkinsonian rat: restoration of bilateral food retrieval by dopamine receptor agonism. Behav Brain Res 169:352-355.

Gasmi M, Brandon EP, Herzog CD, Wilson A, Bishop KM, Hofer EK, Cunningham JJ, Printz MA, Kordower JH, Bartus RT (2007) AAV2mediated delivery of human neurturin to the rat nigrostriatal system: long-term efficacy and tolerability of CERE-120 for Parkinson's disease. Neurobiol Dis 27:67-76.

Gill SS, Patel NK, Hotton GR, O'Sullivan K, McCarter R, Bunnage M, Brooks DJ, Svendsen CN, Heywood P (2003) Direct brain infusion of glial cell line-derived neurotrophic factor in Parkinson disease. Nat Med 9:589-595.

Grondin R, Cass WA, Zhang Z, Stanford JA, Gash DM, Gerhardt GA (2003) Glial cell line-derived neurotrophic factor increases stimulus-evoked dopamine release and motor speed in aged rhesus monkeys. J Neurosci 23:1974-1980.

Hovland DN Jr, Boyd RB, Butt MT, Engelhardt JA, Moxness MS, Ma MH, Emery MG, Ernst NB, Reed RP, Zeller JR, Gash DM, Masterman DM, Potter BM, Cosenza ME, Lightfoot RM (2007) Six-month continuous intraputamenal infusion toxicity study of recombinant methionyl human glial cell line-derived neurotrophic factor $(r-m e t H u G D N F$ in rhesus monkeys. Toxicol Pathol 35:1013-1029.

Jamieson AC, Miller JC, Pabo CO (2003) Drug discovery with engineered zinc-finger proteins. Nat Rev Drug Discov 2:361-368.

Kells AP, Eberling J, Su X, Pivirotto P, Bringas J, Hadaczek P, Narrow WC, Bowers WJ, Federoff HJ, Forsayeth J, Bankiewicz KS (2010) Regeneration of the MPTP-lesioned dopaminergic system after convectionenhanced delivery of AAV2-GDNF. J Neurosci 30:9567-9577.

Lang AE, Gill S, Patel NK, Lozano A, Nutt JG, Penn R, Brooks DJ, Hotton G, Moro E, Heywood P, Brodsky MA, Burchiel K, Kelly P, Dalvi A, Scott B, Stacy M, Turner D, Wooten VG, Elias WJ, Laws ER, et al. (2006) Randomized controlled trial of intraputamenal glial cell line-derived neurotrophic factor infusion in Parkinson disease. Ann Neurol 59:459-466.

Lin LF, Doherty DH, Lile JD, Bektesh S, Collins F (1993) GDNF: a glial cell line-derived neurotrophic factor for midbrain dopaminergic neurons. Science 260:1130-1132.

Liu PQ, Rebar EJ, Zhang L, Liu Q, Jamieson AC, Liang Y, Qi H, Li PX, Chen B, Mendel MC, Zhong X, Lee YL, Eisenberg SP, Spratt SK, Case CC, Wolffe AP (2001) Regulation of an endogenous locus using a panel of designed zinc finger proteins targeted to accessible chromatin regions.
Activation of vascular endothelial growth factor A. J Biol Chem 276:11323-11334.

Manfredsson FP, Burger C, Rising AC, Zuobi-Hasona K, Sullivan LF, Lewin AS, Huang J, Piercefield E, Muzyczka N, Mandel RJ (2009a) Tight longterm dynamic doxycycline responsive nigrostriatal GDNF using a single rAAV vector. Mol Ther 17:1857-1867.

Manfredsson FP, Tumer N, Erdos B, Landa T, Broxson CS, Sullivan LF, Rising AC, Foust KD, Zhang Y, Muzyczka N, Gorbatyuk OS, Scarpace PJ, Mandel RJ (2009b) Nigrostriatal rAAV-mediated GDNF overexpression induces robust weight loss in a rat model of age-related obesity. Mol Ther 17:980-991.

Matsushita T, Elliger S, Elliger C, Podsakoff G, Villarreal L, Kurtzman GJ, Iwaki Y, Colosi P (1998) Adeno-associated virus vectors can be efficiently produced without helper virus. Gene Ther 5:938-945.

Moore M, Choo Y, Klug A (2001a) Design of polyzinc finger peptides with structured linkers. Proc Natl Acad Sci U S A 98:1432-1436.

Moore M, Klug A, Choo Y (2001b) Improved DNA binding specificity from polyzinc finger peptides by using strings of two-finger units. Proc Natl Acad Sci U S A 98:1437-1441.

Oiwa Y, Sanchez-Pernaute R, Harvey-White J, Bankiewicz KS (2003) Progressive and extensive dopaminergic degeneration induced by convection-enhanced delivery of 6-hydroxydopamine into the rat striatum: a novel rodent model of Parkinson disease. J Neurosurg 98:136-144.

Pascual A, Hidalgo-Figueroa M, Piruat JI, Pintado CO, Gómez-Díaz R, López-Barneo J (2008) Absolute requirement of GDNF for adult catecholaminergic neuron survival. Nat Neurosci 11:755-761.

Peterson AL, Nutt JG (2008) Treatment of Parkinson's disease with trophic factors. Neurotherapeutics 5:270-280.

Salvatore MF, Ai Y, Fischer B, Zhang AM, Grondin RC, Zhang Z, Gerhardt GA, Gash DM (2006) Point source concentration of GDNF may explain failure of phase II clinical trial. Exp Neurol 202:497-505.

Sariola H, Saarma M (2003) Novel functions and signalling pathways for GDNF. J Cell Sci 116:3855-3862.

Schallert T, Fleming SM, Leasure JL, Tillerson JL, Bland ST (2000) CNS plasticity and assessment of forelimb sensorimotor outcome in unilateral rat models of stroke, cortical ablation, parkinsonism and spinal cord injury. Neuropharmacology 39:777-787.

Slevin JT, Gerhardt GA, Smith CD, Gash DM, Kryscio R, Young B (2005) Improvement of bilateral motor functions in patients with Parkinson disease through the unilateral intraputaminal infusion of glial cell linederived neurotrophic factor. J Neurosurg 102:216-222.

Su X, Kells AP, Huang EJ, Lee HS, Hadaczek P, Beyer J, Bringas J, Pivirotto P, Penticuff J, Eberling J, Federoff HJ, Forsayeth J, Bankiewicz KS (2009) Safety evaluation of AAV2-GDNF gene transfer into the dopaminergic nigrostriatal pathway in aged and parkinsonian rhesus monkeys. Hum Gene Ther 20:1627-1640.

Tiscornia G, Singer O, Verma IM (2006) Production and purification of lentiviral vectors. Nat Protoc 1:241-245.

Yokoi K, Zhang HS, Kachi S, Balaggan KS, Yu Q, Guschin D, Kunis M, Surosky R, Africa LM, Bainbridge JW, Spratt SK, Gregory PD, Ali RR, Campochiaro PA (2007) Gene transfer of an engineered zinc finger protein enhances the anti-angiogenic defense system. Mol Ther 15:19171923. 